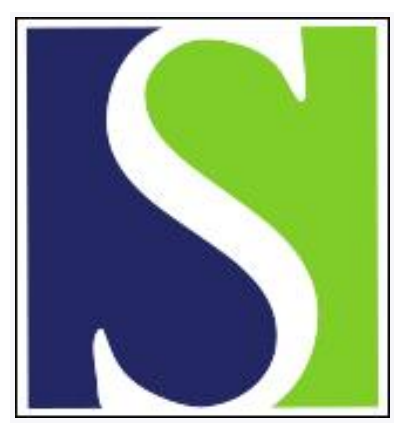

Scand J Work Environ Health 1984;10(2):103-107

https://doi.org/10.5271/sjweh.2360

Issue date: Apr 1984

Lead content of deciduous molar enamel in Finland, as measured by proton-induced $X$-ray emission.

by Jarvinen V, Anttila A, Lappalainen R, Rytomaa I

This article in PubMed: www.ncbi.nlm.nih.gov/pubmed/6089327

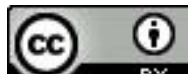




\title{
Lead content of deciduous molar enamel in Finland, as measured by proton-induced X-ray emission
}

\author{
by Varpu Järvinen, LDS, ${ }^{\dagger}$ Anja Anttila, LDS, MSc, ${ }^{1}$ Reijo Lappalainen, $M S c,{ }^{2}$ Inkeri Rytömaa, DDS
}

\begin{abstract}
JÄRVINEN V, ANTTILA A, LAPPALAINEN R, RYTÖMAA I. Lead content of deciduous molar enamel in Finland, as measured by proton-induced X-ray emission. Scand J Work Environ Health 10 (1984) 103-107. The lead content of deciduous molar enamel was measured with an accurate physical technique based on proton-induced X-ray emission. The absolute values were calibrated according to the animal bone standard of the International Atomic Energy Agency. The results obtained from five different communities indicated little difference between communities in the lead content of the deciduous molar enamel of children born in 1960-1975. The overall mean for all samples analyzed was 3.2 (SD 1.6) $\mu \mathrm{g} / \mathrm{g}$ $(\mathrm{N}=120)$; the highest individual value measured was $10.0 \mu \mathrm{g} / \mathrm{g}$. Judging from the lead content of the teeth, the general population in Finland does not yet seem to be exposed to detectably higher amounts of artificially occurring environmental lead, neither in urban nor in rural areas. It would seem that naturally occurring environmental lead still plays a decisive role in the integrated long-term exposure in Finland.
\end{abstract}

Key terms: PIXE, pollution, tooth.

Occupational exposure to high levels of lead is a recognized health hazard (23). On the other hand, the epidemiology of lead poisoning among the general population exposed to medium or low levels of environmental lead is less convincing, partly because integrated long-term exposure to lead is difficult to assess. The amount of lead in deciduous teeth is a potentially useful indicator of cumulative exposure $(2,6,14,23)$, but the reliability of data published thus far has been called into question $(23,24)$. For instance, a recent interlaboratory survey of 13 laboratories in six countries showed that the mean lead concentrations of representative portions of a single homogeneous tooth powder ranged from 4.3 to 15.5 $\mu \mathrm{g} / \mathrm{g}(20)$. These values cover the range believed to be typical of children exposed to low, medium, and high levels of environmental lead.

The most commonly used analytical technique for tooth lead has been atomic absorption spectrophotometry. Recently, proton-induced X-ray emission (PIXE) was shown to be applicable to the analysis of heavy elements in enamel and dentine $(1,13)$. We have adopted this contamination-free technique for the analysis of trace amounts of heavy elements in teeth and developed a method which, with the help of the new bone standard of the International Atomic

1 Institute of Dentistry, University of Helsinki, Helsinki, Finland.

2 Institute of Physics, University of Helsinki, Helsinki, Finland.

Reprint requests to: Dr I Rytömaa, Institute of Dentistry, Mannerheimintie 172, SF-00280 Helsinki, Finland.
Energy Agency (IAEA), will allow measurements that are accurate not only in relative terms but also in absolute quantities. In this presentation we report lead levels in the enamel of deciduous teeth collected from urban and rural areas in Finland.

\section{Material and methods}

Teeth were collected from five different areas of Finland (table 1). Helsinki and Turku are typical Finnish urban areas, and Vantaa is characterized by a relatively heavy industrial use of lead (lead-acid accumulator battery manufacture, paint-industry waste storage). Tervola and Pertunmaa are small rural communities in northern and central Finland, respectively.

Twenty-five deciduous molars were selected for the analysis from each area; because of the small sample size, however, only four molars could be selected from Pertunmaa. The samples were selected from the

Table 1. Total number of deciduous teeth collected and the number of teeth selected for analysis from different localities.

\begin{tabular}{lcc}
\hline Locality & $\begin{array}{c}\text { Number of teeth } \\
\text { collected }\end{array}$ & $\begin{array}{c}\text { Number of deciduous } \\
\text { molars selected } \\
\text { for analysis }\end{array}$ \\
\hline Helsinki & 746 & 25 \\
Turku & 320 & 25 \\
Vantaa & 246 & 25 \\
Tervola & 283 & 25 \\
Pertunmaa & 47 & 4 \\
\hline
\end{tabular}


material collected in such a way that the matching of tooth type and donor age between the different areas was essentially perfect. All the children, born in 1967 -1975 , had lived their whole lives in the same area. In addition to these teeth, 16 deciduous molars collected earlier from Helsinki, Turku, Vantaa, and Tervola, four teeth from each community, were analyzed; the children were born in 1960-1963. Most of the teeth were intact; small carious lesions or amalgam fillings were carefully removed by drilling.
Teeth were dried overnight at $105^{\circ} \mathrm{C}$ and ground to a fine powder in a mechanical mill; enamel and dentine were then separated by the flotation method (12). The enamel powder was compressed into pellets (Specac hydraulic press $\mathrm{P} / \mathrm{N} 15.010$, load 3,000-5,000 kg), $5 \mathrm{~mm}$ in diameter and $0.5-2 \mathrm{~mm}$ thick.

The PIXE method was used for the detection of lead. The proton beam was generated with the $2.5 \mathrm{MV}$ van de Graff accelerator at the University of Helsinki, and the $\mathrm{X}$ rays were detected with a $50-\mathrm{mm}^{2}-\times-6-\mathrm{mm}$

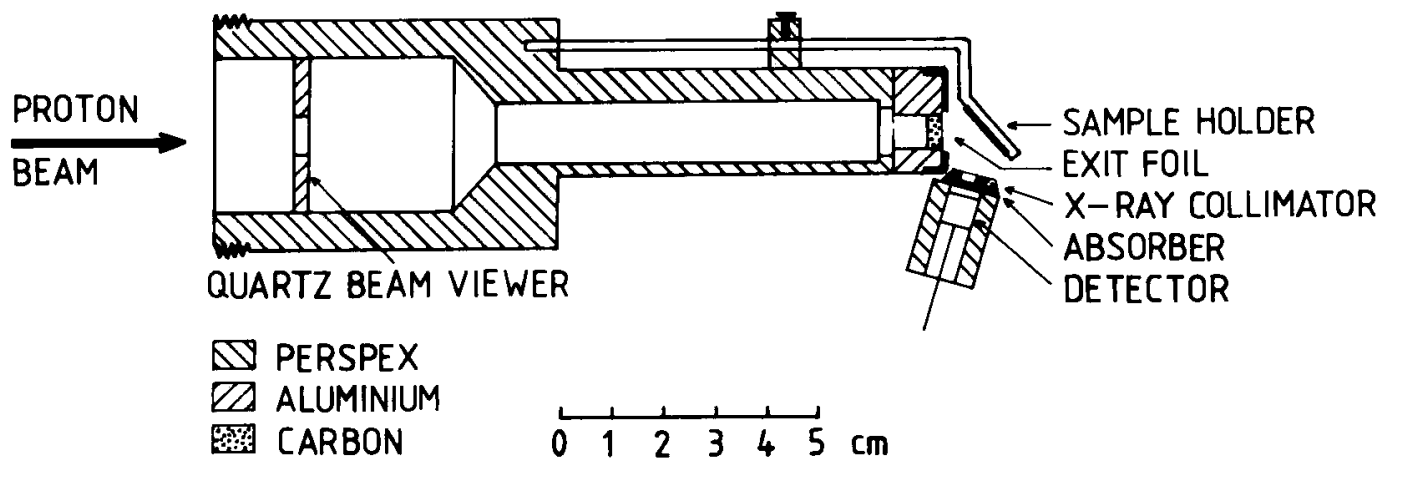

Figure 1. External arrangement of the proton-induced X-ray emission. The cooling arrangement has been omitted in the interest of clarity. The quartz beam viewer and exit foil retaining cap are grounded.

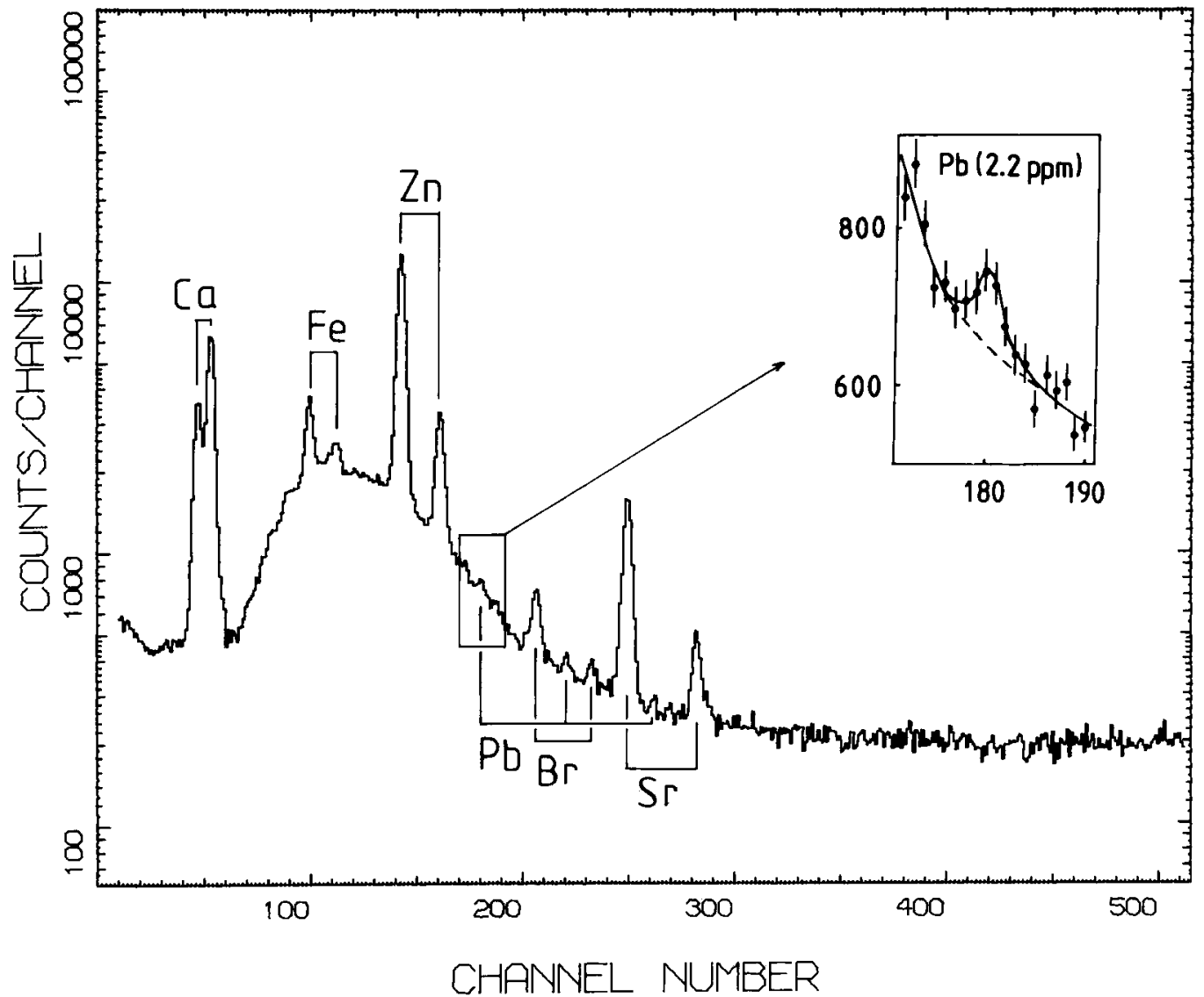

Figure 2. X-ray spectrum of an enamel sample. A plotting constant of 100 has been added to raise the spectrum from the base line. 
intrinsic germanium detector, which had an energy resolution of $180 \mathrm{eV}$ for the Fek $\alpha$ peak during data collection. The X-ray spectra recorded on 1024 channels were stored in the $4 \mathrm{~K}$ memory of a PDP-9 computer. The main features of the experimental set-up used in this study are almost the same as in the work of Räisänen \& Anttila (16), except that the exit foil was made of $7.5-\mu \mathrm{m}$ Kapton ${ }^{(1)}$ foil (Du Pont). The essential feature of the set-up used is that the proton beam is projected into the atmosphere, where the sample can be cooled effectively by nitrogen directed under pressure onto both the sample and the exit foil. Effective cooling is important because the lead concentrations in the teeth are often very low, and thus rather high beam currents are needed. The sample holder is isolated electrically, and direct beam current measurement is therefore possible (see figure 1). The beam current was normally about $100 \mathrm{nA}$, and the beam quantity collected $50 \mu \mathrm{C}$; therefore the measuring period lasted about $10 \mathrm{~min}$. The stability of the beam collection was checked occasionally with the standard sample. The beam spot on the sample was approximately $4 \mathrm{~mm}^{2}$. The extremely high X-ray yield from calcium was reduced with Kapton absorbers.

A typical X-ray spectrum taken from the enamel sample is illustrated in figure 2 . The bromine peaks occurring as impurities in the spectrum of figure 2 originate from the process of separating the enamel and the dentine. Since a rather broad collection of elements is observed simultaneously with the PIXE method, the occurrence of any contaminating material is also normally observed, and thus misleading conclusions can be avoided. Furthermore, since PIXE is nondestructive, the samples can be reanalyzed by other methods if desired.

The lead concentration values were calculated through a comparison of the intensity of the lead $L \alpha$ peaks of the sample with those of the IAEA animal bone (H-5) standard, for which the lead concentration value of 2.97 (SD 0.26) ppm is reported (8). The main composition of the IAEA bone standard is so close to that of the tooth that no correction is necessary to compensate for the stopping power of protons. With measuring periods of $10 \mathrm{~min}$, the detection limit for lead was about $1 \mathrm{ppm}$.

\section{Results}

The mean lead content in the enamel of deciduous molars did not vary much from community to community or between different age groups (table 2). The overall mean for the 120 teeth was 3.2 (SD 1.6) $\mu \mathrm{g} / \mathrm{g}$, and an analysis of variance did not reveal statistically significant differences between the main variables or their interaction. However, when the frequency distributions of the lead values between the four communities (excluding Pertunmaa) were compared with all age groups combined (figure 3 ), a chi-square test revealed a difference at the significance level of $p=$ 0.05 . It can be seen from figure 3 that the main difference was between Turku and Tervola, the rural area of Tervola showing a broader distribution of lead values than the city of Turku.

Teeth affected by caries had a lead content [3.1 (SD 1.4) $\mu \mathrm{g} / \mathrm{g} ; \mathrm{N}=36$ ] similar to that of intact teeth [3.2. (SD 1.6) $\mu \mathrm{g} / \mathrm{g} ; \mathrm{N}=84$ ].

The highest individual lead content measured in the present material was $10.0 \mu \mathrm{g} / \mathrm{g}$. The child was born in 1971 and lived in Vantaa; a retrospective survey from the local health center revealed disturbed mental behavior, but its association with lead "poisoning" is obscure.

\section{Discussion}

The PIXE method is well suited for the analysis of enamel. It can be used even when only a small amount of material is available, as was the case in the present study. Another advantage is that the method is nondestructive and the samples can be reanalyzed with other methods and for other trace elements if desired. In measurements such as those performed in this study the high relative accuracy of PIXE is an obvious advantage. Furthermore, since the new IAEA bone standard is now available, reliable and universally comparable results can be readily obtained.

In the present study only the enamel was analyzed because, on the basis of earlier studies $(7,17)$, it was known that the lead concentration in enamel and dentine are in proportion, but the lead content of the dentine is lower and often near the detection limit of

Table 2. Mean lead content ( $\mathrm{ppm})$ in the enamel of deciduous teeth in different areas in Finland from children born in $1960-$ 1975.

\begin{tabular}{|c|c|c|c|c|c|c|c|c|c|c|c|c|c|c|c|c|c|c|}
\hline \multirow{3}{*}{ Community } & \multicolumn{15}{|c|}{ Year of birth } & \multirow{2}{*}{\multicolumn{3}{|c|}{ Community mean }} \\
\hline & \multicolumn{3}{|c|}{$1960-1963$} & \multicolumn{3}{|c|}{$1967-1968$} & \multicolumn{3}{|c|}{$1969-1970$} & \multicolumn{3}{|c|}{$1971-1972$} & \multicolumn{3}{|c|}{$1973-1975$} & & & \\
\hline & $\mathrm{N}^{\mathrm{a}}$ & Mean & $\overline{S D}$ & $\mathrm{~N}^{\mathrm{a}}$ & Mean & $\overline{S D}$ & $\mathrm{~N}^{\mathrm{a}}$ & Mean & $\overline{S D}$ & $\mathrm{Na}^{a}$ & Mean & $\overline{\mathrm{SD}}$ & $\mathrm{Na}^{\mathrm{a}}$ & Mean & $\overline{\mathrm{SD}}$ & $\mathrm{N}^{2}$ & Mean & $\mathrm{SD}$ \\
\hline $\begin{array}{l}\text { Helsinki } \\
\text { Turku } \\
\text { Vantaa } \\
\text { Tervola } \\
\text { Pertunmaa }\end{array}$ & $\begin{array}{r}4 \\
4 \\
4 \\
4 \\
\end{array}$ & $\begin{array}{l}2.2 \\
3.4 \\
3.5 \\
1.7 \\
\ldots\end{array}$ & $\begin{array}{l}0.8 \\
0.4 \\
1.4 \\
1.0 \\
\ldots\end{array}$ & $\begin{array}{r}2 \\
3 \\
4 \\
5 \\
\ldots\end{array}$ & $\begin{array}{l}3.4 \\
2.3 \\
2.4 \\
4.7 \\
\ldots\end{array}$ & $\begin{array}{l}3.0 \\
0.8 \\
0.8 \\
1.4 \\
\cdots\end{array}$ & $\begin{array}{r}7 \\
10 \\
4 \\
7 \\
2\end{array}$ & $\begin{array}{l}3.1 \\
2.8 \\
3.4 \\
4.6 \\
2.3\end{array}$ & $\begin{array}{l}1.9 \\
1.2 \\
1.4 \\
2.0 \\
0.0\end{array}$ & $\begin{array}{r}10 \\
6 \\
10 \\
7 \\
2\end{array}$ & $\begin{array}{l}3.9 \\
2.9 \\
3.8 \\
3.1 \\
2.1\end{array}$ & $\begin{array}{l}1.6 \\
1.4 \\
2.4 \\
1.3 \\
0.4\end{array}$ & $\begin{array}{l}6 \\
6 \\
7 \\
6 \\
\cdots\end{array}$ & $\begin{array}{c}3.3 \\
2.2 \\
2.8 \\
3.2 \\
\ldots\end{array}$ & $\begin{array}{l}1.3 \\
1.1 \\
1.3 \\
0.8 \\
\cdots\end{array}$ & $\begin{array}{r}29 \\
29 \\
29 \\
29 \\
4\end{array}$ & $\begin{array}{l}3.3 \\
2.7 \\
3.3 \\
3.6 \\
2.2\end{array}$ & $\begin{array}{l}1.6 \\
1.1 \\
1.7 \\
1.7 \\
0.3\end{array}$ \\
\hline Age group mean & 16 & 2.7 & 1.2 & 14 & 3.3 & 1.7 & 30 & 3.4 & 1.7 & 35 & 3.4 & 1.8 & 25 & 2.9 & 1.1 & 120 & 3.2 & 1.6 \\
\hline
\end{tabular}

a $\mathrm{N}=$ number of samples (children) analyzed. 


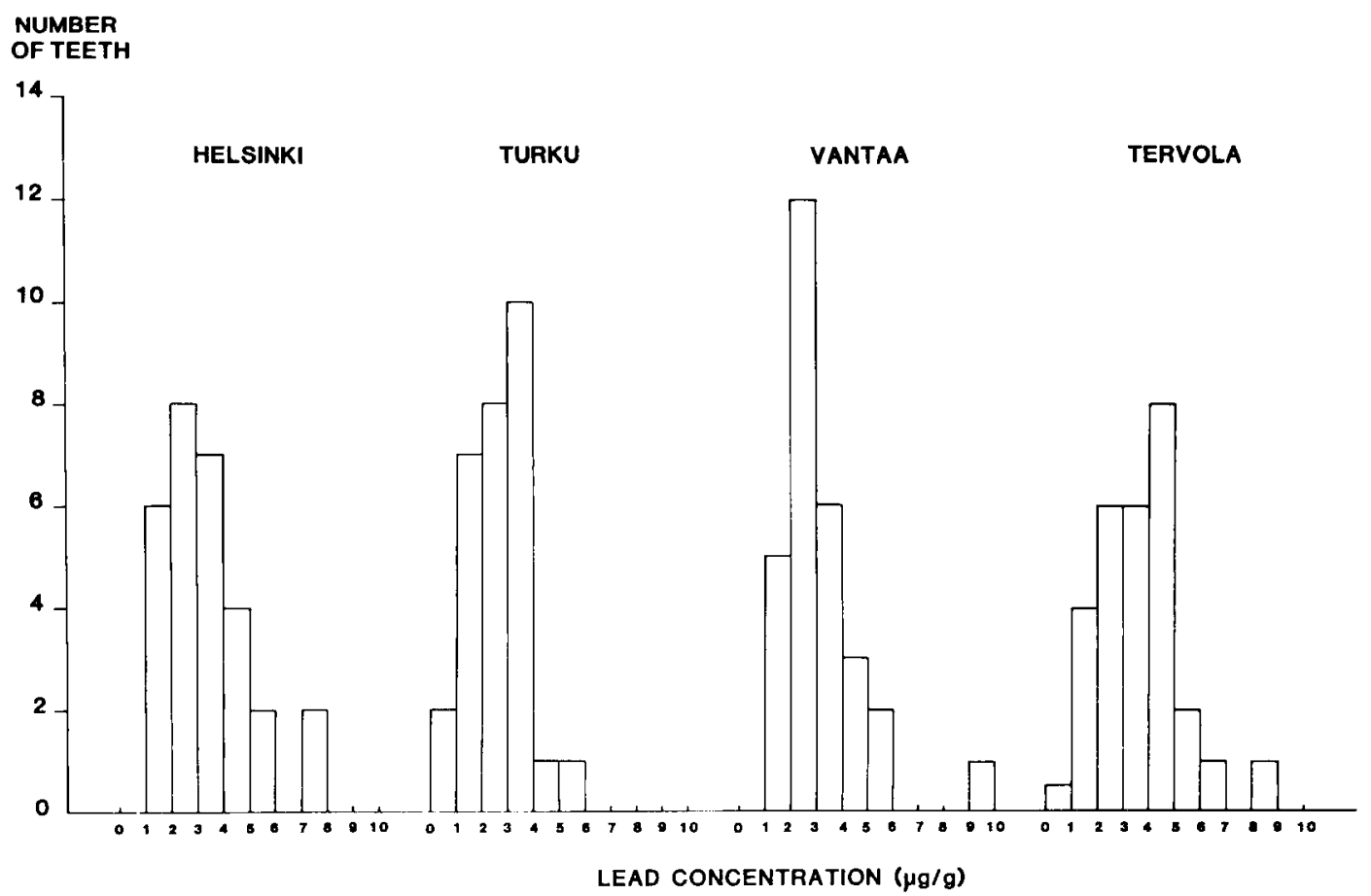

Figure 3. The distribution of lead levels in the enamel of deciduous teeth from four different areas in Finland. The number of teeth is equal to the number of children studied.

about $1 \mathrm{ppm}$. In one of these studies (17), however, the absolute values are too high, perhaps because of the lack of proper reference material. The separation of enamel and dentine is also useful for control purposes. For instance, if an exceptionally high lead value is detected in the enamel, a complementary dentine measurement can determine whether the origin of the lead is acute and exogenous or derived on a long-term basis through the blood circulation during tooth formation.

The present study shows that the lead content of deciduous molar enamel in Finland is low, an overall average of $3.2 \mathrm{ppm}$.

Other recent studies have also detected relatively low levels of tooth lead in Finland $(7,9)$. For instance, permanent tooth enamel in urban samples from the city of Kuopio contained $5.8 \mathrm{ppm}$, and rural samples $4.9 \mathrm{ppm}$ of lead, when measured with atomic absorption spectrometry (9). With the PIXE technique the lead content of deciduous tooth enamel was 4.5 ppm in Kuopio and $4.2 \mathrm{ppm}$ in Helsinki (7). Even these values are slightly higher than those measured in the present study, but the difference is probably explained by the type of teeth analyzed. It has previously been reported that deciduous incisors and canines contain more lead than molars (19).

When the lead content of deciduous teeth from the urban areas Helsinki and Turku, and from Vantaa, where there is a relatively heavy industrial use of lead, was compared with that of deciduous teeth from rural areas, the supposedly higher exposure to lead was not revealed. This finding is in accordance with measurements of lead concentrations in blood, which reflect short-term exposure, because no difference has been found between Finnish urban and rural areas (22). A similar situation has been reported from Norway on the basis of an analysis of a fairly large sample of 2,233 teeth (6). In Sweden, Möller et al (13) found that the lead content of teeth was about $1 \mathrm{ppm}$ higher in large cities than in rural areas, and they interpreted this result as reflecting different traffic densities.

In the present study the mean content of lead in deciduous enamel was actually highest in Tervola, a small rural area located in northern Finland. Because this result is not caused by high traffic density, other explanations are necessary. One apparent possibility is the somewhat higher lead concentration in the drinking water of Tervola than in the drinking water of the other communities studied (according to the unpublished results of the Geological Survey of Finland, Department of Quaternary Geology), a phenomenon which in turn may be associated with the aboveaverage concentration of primordial radionuclides in the soil [see the report of Castren et al (4)].

Tooth lead content in Finland $(7,9)$, Norway (3, 6), and Sweden (13) is lower than in the United States $(14,18)$. This difference is clearly not a result of methodological factors because the same measuring technique (PIXE) showed (13) that the lead content in permanent tooth enamel was three times higher in samples collected in New York than in samples 
collected in Stockholm.

The present sample, consisting of 120 children, may not be large enough to allow specific statements about the lead contamination and exposure in Finland. However, in view of the high relative and absolute accuracy of the present measurements, the finding that even the highest individual lead content measured was lower than the mean values reported from large cities in some other countries $(5,6,10,11,13,14,18$, 21) shows that exposure to lead from generalized sources such as traffic has not yet become a major concern in Finland. Similar observations have been made before from urban and rural blood lead levels in Finland $(15,22)$.

In conclusion, it appears that the general population in Finland, and also in the other Nordic countries, has not yet been exposed to artificially occurring environmental lead to the extent that it would be significant in the integrated long-term exposure to this potentially harmful element.

\section{Acknowledgments}

We wish to thank the personnel of the dental clinics in the health centers in Helsinki, Kuopio, Pertunmaa, Tervola, Turku, and Vantaa.

This study was supported by a grant from Suomen Naishammaslääkärit ry (Association of Finnish Women Dentists).

\section{References}

1. Ahlberg M, Akselsson R. Proton-induced x-ray emission in the trace analysis of human tooth enamel and dentine. Int J Appl Radiat Isot 27 (1976) 279-290.

2. Altshuller LF, Halak DB, Landing BH, Kehoe RA. Deciduous teeth as an index of body burden of lead. $\mathbf{J}$ Pediatr 60 (1962) 224-229.

3. Attramadal A, Jonsen $\mathbf{J}$. The content of lead, cadmium, zinc and copper in deciduous and permanent human teeth. Acta Odontol Scand 34 (1976) 127-131.

4. Castren $\mathrm{O}$, Winqvist $\mathrm{K}$, Mäkeläinen I, Voutilainen A. Radon Suomen asunnoissa. STL-B-TUTO XX. Institute of Radiation Protection, Helsinki 1983.

5. Evers U, Brockhaus A, Genter E, Idel H, Schürmann EA. Untersuchungen über den Zahnbleigehalt von Schulkindern aus zwei unterschiedlich belasteten Gebieten in Nordwestdeutschland. Int Arch Environ Health 44 (1979) 65-80.

6. Fosse G, Berg Justesen N-P. Lead in deciduous teeth of Norwegian children. Arch Environ Health 33 (1978) $166-175$.

7. Haavikko K, Anttila A, Helle A, Vuori E. The lead concentrations of enamel and dentine of deciduous teeth of children from two Finnish towns. Arch Environ Health (in press).

8. International Atomic Energy Agency. Intercomparison of minor trace elements in IAEA Animal Bone ( $\mathrm{H}-5)$. Vienna 1982. (Progress report no 1).

9. Lappalainen $R$, Knuuttila $M$. The concentrations of $\mathrm{Pb}, \mathrm{Cu}, \mathrm{Cr}$ and $\mathrm{Ni}$ in extracted permanent teeth related to donors' age and element in the soil. Acta Odontol Scand 39 (1981) 163-167 \& 247-248.

10. Lockeretz W. Lead content of deciduous teeth of children in different environments. Arch Environ Health 30 (1975) 583-587.

11. Mackie AC, Stephens R, Townshend A. Tooth lead levels in Birmingham children. Arch Environ Health 32 (1977) $178-185$.

12. Manly RS, Hodge HG. Density and retractive index studies of dental hard tissue. J Dent Res 18 (1939) $133-141$.

13. Möller B, Carlsson L-E, Johansson GI, Malmqvist G, Hammarström L, Berlin M. Lead levels determined in Swedish permanent teeth by particle-induced X-ray emission. Scand J Work Environ Health 8 (1982) $267-272$.

14. Needleman HL, Tuncay OC, Shapiro YM. Lead levels in deciduous teeth of urban and suburban American children. Nature 235 (1972) 111-112.

15. Nordman CH. Environmental lead exposure in Finland: A study on selected population groups. Institute of Occupational Health, Helsinki 1975. (Academic dissertation).

16. Räisänen I, Anttila A. On a selection of beam exit window materials for PIXE analysis. Nucl Instrum Methods 196 (1982) 489-492.

17. Rytömaa I, Tuompo H. Lead levels in deciduous teeth. Naturwissenschaften 61 (1974) 363.

18. Shapiro IM, Needleman HL, Tuncay OC. The lead content of human deciduous and permanent teeth. Environ Res 5 (1972) 467-470.

19. Stack MV. Lead. In: Curzon MEJ, Cutress TW, ed. Trace elements and dental diseases. John Wright P SG, Inc, Boston, Bristol, London 1983, p 364.

20. Stack MV, Delves HT. Tooth-lead analysis: An interlaboratory survey. In: Egan H, West TS, ed. Collaborative interlaboratory studies in chemical analysis. Pergamon Press, Oxford 1982, pp 115-118.

21. Stewart DJ. Teeth as indicators of exposure of children to lead. Arch Dis Child 49 (1974) 895-897.

22. Taskinen $H$, Nordman $H$, Engström K, Hernberg S. Blood lead levels in Finnish preschool children. Sci Total Environ 20 (1981) 117-129.

23. World Health Organization. Lead. Geneva 1977. (WHO environmental health criteria 3 ).

24. $\div$. Editorial. Dev Med Child Neurol 23 (1981) 565 .

Received for publication: 31 January 1984 